\title{
Adsorption Behaviour of La(III) and Eu(III) Ions from Aqueous Solutions by Hydroxyapatite: Kinetic, Isotherm, and Thermodynamic Studies
}

\author{
F. Granados-Correa, ${ }^{1}$ J. Vilchis-Granados, ${ }^{1,2}$ M. Jiménez-Reyes, ${ }^{1}$ and L. A. Quiroz-Granados ${ }^{2}$ \\ ${ }^{1}$ Departamento de Química, Instituto Nacional de Investigaciones Nucleares, P.O. Box 18-1027, Colonia Escandón, \\ Delegación Miguel Hidalgo, 11801 Mexico City, DF, Mexico \\ ${ }^{2}$ Instituto Tecnológico de Zitácuaro, Ex Hacienda de Manzanillos S/N. Colonia Mojonera, 61500 Zitácuaro, Michoacán, Mexico
}

Correspondence should be addressed to F. Granados-Correa; francisco.granados@inin.gob.mx

Received 20 June 2012; Accepted 29 August 2012

Academic Editor: Patricia Valentao

Copyright (C) 2013 F. Granados-Correa et al. This is an open access article distributed under the Creative Commons Attribution License, which permits unrestricted use, distribution, and reproduction in any medium, provided the original work is properly cited.

\begin{abstract}
The hydroxyapatite was successfully synthesized, characterized, and used as an alternative low-cost adsorbent material to study the adsorption behavior of $\mathrm{La}$ (III) and $\mathrm{Eu}$ (III) ions from nitrate aqueous solutions as a function of contact time, initial metal ion concentration, $\mathrm{pH}$, and temperature by using a bath technique. The kinetic data correspond very well to the pseudo-second-order equation, and in both cases the uptake was affected by intraparticle diffusion. Isotherm adsorption data were well fitted by the Freundlich model equation with $1 / n>1$, indicating a multilayer and cooperative-type adsorption. Thermodynamic parameters for the adsorption systems were determinated at 293, 303, 313, and $323 \mathrm{~K}$. These parameters show that adsorptions of La(III) and $\mathrm{Eu}(\mathrm{III})$ ions on hydroxyapatite are endothermic and spontaneous processes. The adsorption was found to follow the order Eu(III) $>$ $\mathrm{La}(\mathrm{III})$ and is dependent on ion concentration, $\mathrm{pH}$, and temperature.
\end{abstract}

\section{Introduction}

The concentration of the polluting agents in the effluents has increased considerably due to its excessive use in the industrial and nuclear processes and to their unloading without previous treatment [1-3]. Therefore, the water contamination by chemical substances, of high toxicity degree for living beings, such as arsenic, barium, cadmium, cyanide, cobalt, cuprum, chromium, and rare earth elements (REEs) has been a problem of special interest in the environmental area during the past few years. Recently, adsorption as process for treating contaminated water has been object of several investigations because this method allows removal of a great amount of watery polluting agents on several types of organic and inorganic adsorbent materials; moreover, this method has shown to be economic and highly effective [4]. There are a great variety of natural or synthetic inorganic materials with different chemical, structural, and superficial characteristics that have been used as adsorbent materials in processes of demineralization and elimination of heavy metals from water. In general, their porous structures and high superficial areas of these materials favor the ion adsorption.

Hydroxyapatite $\mathrm{Ca}_{10}\left(\mathrm{PO}_{4}\right)_{6}(\mathrm{OH})_{2}$ has been identified as a promising material for environmental process because it has a high affinity for the adsorption of many polluting agents of nuclear and environmental interest. Its characteristics have been well documented, and their mechanisms of retention depend upon the metal chemical species [5-9].

Hydroxyapatite is a crystalline solid whose properties make it an ideal backfill material in nuclear waste repositories as adsorbent. Its crystallographic structure arranged in a hexagonal system is formed by a hexagonal stack of isolated $\mathrm{PO}_{4}{ }^{3-}$ tetrahedrons creating tunnels. It exhibits a high stability under reducing and oxidizing conditions over a wide temperature range. When it is treated at high temperature, it gives apatite with ion exchanger properties; moreover, hydroxyapatite can act as a host to small molecules [10]. In addition, hydroxyapatite exhibits a very low water solubility 
$\left(K_{\mathrm{sp}}<10^{-40}\right)$ under alkaline conditions and is available at a low cost.

The hydroxyapatite, as the most representative form of apatite minerals, is present in metamorphic rocks, sediments, grounds, and suspended particles and has widely been used as a substitute for bone and teeth because its mineral components are similar to both bone and teeth [11]. The hydroxyapatite can be obtained naturally from calcination of animal bones [12]; it can also be produced synthetically through precipitation from aqueous solutions containing calcium and phosphates [13], from high-temperature solidstate reactions [14], from an aqueous solution combustion technique $[15,16]$, or from hydrothermal synthesis [17]. Hydroxyapatite can also be mined, but in this case the purity is typically low [18].

In the context of the safety of nuclear waste repositories, as well as for assessing radionuclide mobility in the environment or industrial wastes, the interaction among lanthanides and actinides with sorbents has become a main subject of many studies. Several models have been proposed to explain the complex formation (e.g., nonelectrostatic and diffuse layer among others). Lanthanum and europium belong to the REE; only their trivalent oxidation states are stable in aqueous solutions. Their chemical behaviors have been considered typical of REE and of some trivalent actinides as well. In contrast, both lanthanum and europium are used mainly in the manufacture of cathode ray tubes, fluorescent lamp, and screen for X-rays; in the nuclear industry europium is used as absorbent of neutrons for the extinction and control rods of the reactors. The isotopes of these elements are considered toxic for the human health [19]. Thus, the study of La(III) and $\mathrm{Eu}$ (III) adsorption on inorganic materials is essential for the control of these elements in the environment. Also, the study of adsorption kinetics in wastewater treatment is important in providing valuable insights into the reaction pathways and into the mechanism of adsorption reaction. Indeed, lanthanum and europium adsorption on several materials is now well understood [20-36]. However, as far as we know studies about their adsorption on hydroxyapatite have not been done.

The purpose of this study was to investigate the adsorption behavior of $\mathrm{La}$ (III) and $\mathrm{Eu}$ (III) ions from nitrate aqueous solution onto synthetic hydroxyapatite and to evaluate the potential of this material to adsorb these REE ions. These studies were dedicated to the synthesis process, physicochemical characterization of the synthesized powder, and to the description of adsorption process. The kinetics, equilibrium, and thermodynamics parameters of the adsorption of those REE ions onto synthetic hydroxyapatite have been analyzed and discussed in the light of current known models available in open literature, and relevant parameters were determined.

\section{Experimental}

2.1. Synthesis and Characterization of Hydroxyapatite. Hydro-xyapatite powder was chemically synthesized by wet chemical precipitation method, followed by calcination according to the procedure reported by Kannan et al. [37]; calcium nitrate tetrahydrate $\mathrm{Ca}\left(\mathrm{NO}_{3}\right)_{2} \cdot 4 \mathrm{H}_{2} \mathrm{O}$ (Aldrich) and diammonium hydrogen phosphate $\left(\mathrm{NH}_{4}\right)_{2} \mathrm{HPO}_{4}$ (Aldrich) were used as starting chemical precursors of analytical grade without further purification. The obtained powders were heat treated at $1050^{\circ} \mathrm{C}$ for $2 \mathrm{~h}$; the resulting material was used for later characterization and to measure its adsorption capacity for $\mathrm{La}(\mathrm{III})$ and $\mathrm{Eu}(\mathrm{III})$. To know the purity and crystalline structure of the synthesized hydroxyapatite, a diffractometer Siemens D-5000 connected to an X-ray tube of copper anode was used. The $K_{\alpha}$ was selected by means of a monochromator of diffracted beam. The diffraction pattern was scanned with a sweeping of $5^{\circ}$ to $70^{\circ}$ in $2 \theta$ angle, with a counting time of $0.07 \mathrm{~s}$ per step. The spectra were compared with the Joint Committee on Powder Diffraction Standards (JCPDS) files. The specific surface area, average pore radius and total pore volume of the synthesized material, were determined by the Brunauer-Emmett-Teller (BET) method with a Belsorp-max equipment; the samples were heated at $60^{\circ} \mathrm{C}$ for $8 \mathrm{~h}$ before specific surface areas were measured.

An Infrared Spectroscopy (IR) analysis was done using an IR Nicolette 550 spectrophotometer via the conventional method of $\mathrm{KBr}$ disc. The morphology and grain size of the prepared hydroxyapatite powders were determined using a JEOL-JMS 5900 LV Scanning Electron Microscopy (SEM). The chemical composition of the hydroxyapatite synthesized was analyzed by Energy Dispersive Spectrometry (EDS) connected to a JEOL-JMS 5900 system. Determinations for acidic and basic surface sites on hydroxyapatite were generated by potentiometric titration proposed by Boehm and Voll [38] using $\mathrm{NaOH} 0.1 \mathrm{~mol} / \mathrm{L}$ and $\mathrm{HCl} 0.1 \mathrm{~mol} / \mathrm{L}$ solutions, respectively. Mass titration method was applied to determine the zero point charge (zpc) of the hydroxyapatite surface by means of $\mathrm{pH}$ measurements, using an inert electrolyte solution of $\mathrm{KNO}_{3}$ at $25^{\circ} \mathrm{C}$ under a nitrogen-controlled atmosphere, adjusted by addition of $\mathrm{HNO}_{3}$ or $\mathrm{KOH}$ solutions under continuous agitation by 24 hours [39].

2.2. Adsorption Studies. These studies were carried out by batch technique at room temperature and pressure to obtain rate and equilibrium data. The stock solutions of $\mathrm{La}(\mathrm{III})$ and $\mathrm{Eu}(\mathrm{III})$ were prepared by dissolving a known quantity of both $\mathrm{La}\left(\mathrm{NO}_{3}\right)_{3} \cdot 6 \mathrm{H}_{2} \mathrm{O}(99.9 \%$ Aldrich $)$ and $\mathrm{Eu}\left(\mathrm{NO}_{3}\right)_{3} \cdot 5 \mathrm{H}_{2} \mathrm{O}$ (99.9\% Aldrich), respectively, in distilled water (natural $\mathrm{pHs}=6.0$ for both ions). Other solutions were prepared by successive dilutions of the stocks.

Adsorption studies were performed by shaking $0.1 \mathrm{~g}$ of hydroxyapatite and $10 \mathrm{~mL}$ of each individual metal ion solution in closed vials; after a specific contact time the solid was separated from the liquid by centrifugation (5 minutes at $3000 \mathrm{rpm}$ ), and the clear supernatant was analyzed for metal ion concentration. All experimental data were considered as the average of duplicate determinations; a good reproducibility was obtained; standard deviations were usually less than $5 \%$ of mean values.) The $\mathrm{pH}$ values of the supernatants measured at the end of the experiments were assumed to be equilibrium $\mathrm{pH}$ and they were $5.7 \pm 0.03$. A digital pHmeter (Cole-Parmer model 05669-20), combined with a glass electrode, was used for these measurements. 
Initial and final $\mathrm{La}(\mathrm{III})$ and $\mathrm{Eu}(\mathrm{III})$ concentrations in solution were determined with a Shimadzu ultraviolet-visible 265 spectrophotometer by means of the xylenol orange method at $575 \mathrm{~nm}$ and $575.3 \mathrm{~nm}$, respectively [40]. The experimental calibration lines were: absorption $=30469$ $[\mathrm{La}(\mathrm{III})]$ and absorption $=26253[\mathrm{Eu}(\mathrm{III})]$. Aliquots of $2 \mathrm{~mL}$ of the clear supernatant were mixed with $3 \mathrm{~mL}$ of a $4.5 \times$ $10^{-4} \mathrm{~mol} / \mathrm{L}$ xilenol orange solution; a final volume of $10 \mathrm{~mL}$ was completed with a buffer solution (acetic acid/sodium acetate) of $\mathrm{pH}=5.6$. The amounts of $\mathrm{La}(\mathrm{III})$ and $\mathrm{Eu}(\mathrm{III})$ ions adsorbed per gram of hydroxyapatite at a specific contact time $\left(q_{t}\right)$ or at equilibrium $\left(q_{e}\right)$ were determined by the following equation:

$$
q_{t} \text { or } q_{e}=\frac{\left(C_{i}-C_{f}\right) V}{w}
$$

where $q_{t}$ and $q_{e}$ are the amount of REE ions adsorbed in $\mathrm{mg} / \mathrm{g}$ at time $t$ or at equilibrium, respectively, $C_{i}$ and $C_{f}$ are the initial and final REE ion concentration in the solution $(\mathrm{mg} / \mathrm{L}) ; V$ is the volume of the solutions $(0.01 \mathrm{~L})$, and $w$ is the mass of hydroxyapatite $(0.1 \mathrm{~g})$. The distribution coefficient was calculated as follows: $K_{d}=q_{e} / C_{f}$.

Kinetic data were obtained at various intervals of time $\left(1-60\right.$ minutes; $[\mathrm{La}(\mathrm{III})]=5.7 \times 10^{-5} \mathrm{~mol} / \mathrm{L}$ and $[$ EuIII $\left.)\right]=6.5$ $\times 10^{-5} \mathrm{~mol} / \mathrm{L}$ ), and they were evaluated using several models. After fixing the optimal time for equilibrium, isotherms and thermodynamic studies were done; these data were mathematically treated as well.

\section{Results and Discussion}

3.1. Hydroxyapatite Characterization. According to crystal structure analyses performed by $\mathrm{X}$-ray diffraction, a pure and well-crystallized sample was obtained with only one phase (Figure 1). This diffractogram is typical of hydroxyapatite as compared and identified with the JCPDS file 01-04-3708. The specific surface area, measured by BET method, was found to be $59.70 \mathrm{~m}^{2} / \mathrm{g}$; the total pore volume was $0.112 \mathrm{~cm}^{3} / \mathrm{g}$, and the pore diameter was $7.50 \mathrm{~nm}$.

Infrared analyses confirmed the purity of the hydroxyapatite, whose characteristic absorption bands observed in the spectrum (Figure no showed) were as follows: at $962.6 \mathrm{~cm}^{-1}$ and $1040 \mathrm{~cm}^{-1}$ attributed to the presence of $\mathrm{PO}_{4}{ }^{3-}$ groups; a low-intensity band at $957 \mathrm{~cm}^{-1}$ attributed at $\mathrm{P}-\mathrm{OH}$ groups; at $3431.39 \mathrm{~cm}^{-1}$ as a result from the hydrogen vibrations and a broad band at $1032.9 \mathrm{~cm}^{-1}$ that indicates the presence of $\mathrm{OH}^{-}$groups near the solid surface. Other species were not observed in the spectrum.

The micrographs, obtained by SEM (Figure 2), show that the synthetic hydroxyapatite used in this work is composed of rhombus geometry and layered porous particles with approximate diameters between 10 to $100 \mu \mathrm{m}$. Figure 2 also shows the EDS analysis of the synthesized material, revealing only the presence of carbon (due to the supporting ribbon), oxygen, phosphorus, and calcium in the material. The experimental ratio $\mathrm{Ca}: \mathrm{P}(2.1)$ is in agreement with the stoichiometric value.

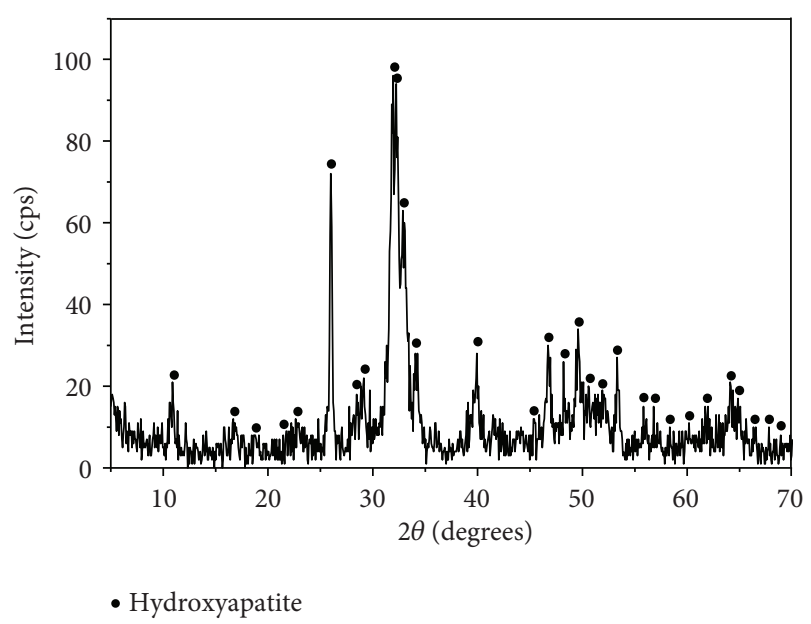

FIGURE 1: X-ray diffraction (XRD) pattern of synthetic hydroxyapatite sample.

The synthetic hydroxyapatite sample has an acidic surface character because $3.70 \mathrm{meq} / \mathrm{g}$ of acidic surface sites was obtained in comparison with $0.37 \mathrm{meq} / \mathrm{g}$ of basic surface sites. The zpc value for the synthetic hydroxyapatite was 7.68; this result is in agreement with the values reported in literature $[41,42]$.

3.2. Adsorption Kinetics. Figure 3 shows the effect of contact time upon the metal ion adsorption on hydroxyapatite. The figure represents the amounts in $\mathrm{mg}$ of $\mathrm{La}(\mathrm{III})$ or $\mathrm{Eu}(\mathrm{III})$ ions adsorbed per gram of synthetic hydroxyapatite as a function of contact time at room temperature.

As can be seen in Figure 3, the $\mathrm{La}(\mathrm{III})$ and $\mathrm{Eu}(\mathrm{III})$ adsorption on hydroxyapatite occurs quickly; 20 to 30 minutes are enough to achieve their adsorption equilibria. The $q_{\max }$ values for $t \geq 20$ minutes were $0.25 \pm 0.01 \mathrm{mg} / \mathrm{g}$ for $\mathrm{La}(\mathrm{III})$ and $0.94 \pm 0.01 \mathrm{mg} / \mathrm{g}$ for $\mathrm{Eu}(\mathrm{III})$. These fast ion adsorptions are certainly related to the high dispersion degree of adsorbent as well as the high availability of external specific surface area. These results are important from the point of view of the efficiency of adsorption technologies; in just a short time, adsorption allows removal of these polluting agents, which translates into reduced operating and processing costs.

The kinetics of adsorption describe the adsorbate adsorption rate, which in turn governs the residence time of adsorption reaction. It is one of the important characteristics in defining the efficiency of adsorption. To investigate the kinetic parameters for both $\mathrm{La}$ (III) and $\mathrm{Eu}$ (III) adsorptions by hydroxyapatite at room temperature, the data were analyzed by means of the following models: pseudo-first-order [43], Elovich [44], pseudo-second-order [45], and intraparticle mass transfer diffusion [46]. For the two first models $R^{2}$ values were $\leq 0.97$; whereas for both $\mathrm{La}$ (III) and $\mathrm{Eu}$ (III) adsorptions on hydroxyapatite the best fitting $\left(R^{2}>0.999\right)$ was obtained by means of the pseudo-second-order equation (see Table 1). This model is based on the assumption that the rate-limiting step may be chemisorption involving valence 


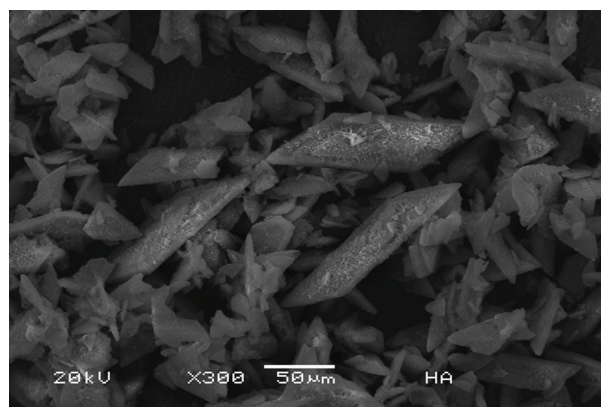

(a)

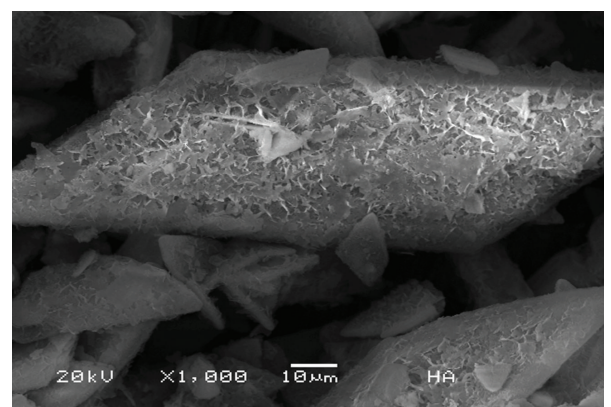

(b)

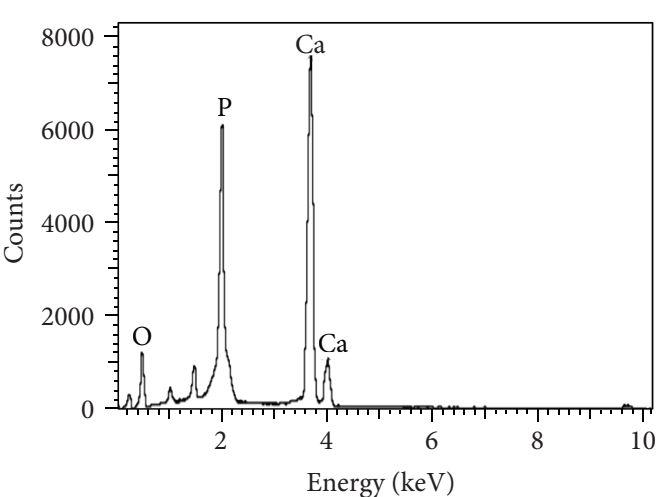

\begin{tabular}{|c|c|c|}
\hline Element & Element (\%) & Atomic (\%) \\
\hline $\mathrm{C}$ & 7.45 & 13.67 \\
\hline $\mathrm{O}$ & 39.44 & 54.35 \\
\hline $\mathrm{P}$ & 17.05 & 12.13 \\
\hline $\mathrm{Ca}$ & 36.04 & 19.82 \\
\hline
\end{tabular}

FIgURE 2: MEB micrographs (a) 300x, (b) 1000x and EDS analyses of synthetic hydroxyapatite sample.

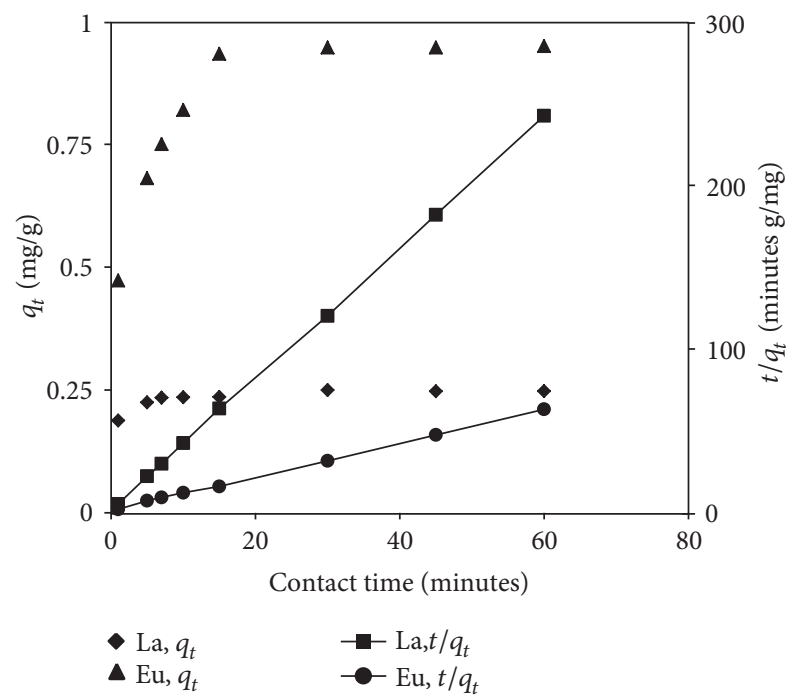

FIgURE 3: Amount of REEs adsorbed on synthetic hydroxyapatite $\left(q_{t}\right)$ and fitting of the data to the pseudo-second-order model $\left(t / q_{t}\right)$ both of them as a function of contact time. $[\mathrm{La}(\mathrm{III})]_{\mathrm{i}}=5.7 \times$ $10^{-5} \mathrm{~mol} / \mathrm{L} ;[\mathrm{Eu}(\mathrm{III})]_{\mathrm{i}}=6.5 \times 10^{-5} \mathrm{~mol} / \mathrm{L}$. The equations of the lines are: $t / q_{t}=4.0+1.88 t\left(R^{2}=0.9999\right)$ for $\mathrm{La}(\mathrm{III})$ and $t / q_{t}=1.02+1.60 t$ $\left(R^{2}=0.9999\right)$ for $\mathrm{Eu}(\mathrm{III})$.

forces through sharing or exchange of electrons between adsorbent and adsorbate.

The results corresponding to the intraparticle mass transfer diffusion model are included in Table 1 and Figure 4. The first linear portion corresponds to the macropore diffusion and being $C=0$, the boundary-layer effect can be considered as minimal for $t \leq 1$ minute. The second portion describes the micropore diffusion before equilibrium is attained. Both macropore and diffusions are faster for $\mathrm{Eu}(\mathrm{III})$ than for $\mathrm{La}(\mathrm{III})$. Finally, the third horizontal line describes the equilibrium condition, where $C=q_{\max }$.

A comparison of the $q_{\max }$ values obtained for the La(III) and $\mathrm{Eu}(\mathrm{III})$ adsorption on hydroxyapatite with those data collected in literature about the adsorption of these REE on different inorganic materials is shown in Table 2. These data show that synthetic hydroxyapatite exhibits an adsorption capacity toward $\mathrm{La}(\mathrm{III})$ and $\mathrm{Eu}(\mathrm{III})$; moreover, this material can be useful for removing REE from aqueous solutions.

3.3. Adsorption Isotherms. An adsorption isotherm is characterized by certain constants whose values express the surface properties and affinity of the adsorbent that can also be used to find the adsorptive capacity of adsorbent at equilibrium. Thus, the equilibrium distributions of La(III) and $\mathrm{Eu}(\mathrm{III})$ ions between the liquid phase and the solid adsorbent phase (hydroxyapatite) were studied as a function of ion initial concentrations. The initial concentration ranges were $3.3 \times 10^{-5}-2.2 \times 10^{-4} \mathrm{~mol} / \mathrm{L}$ and $1.7 \times 10^{-4}-3.6 \times$ $10^{-4} \mathrm{~mol} / \mathrm{L}$ for lanthanum and $1.9 \times 10^{-4}-4 \times 10^{-4} \mathrm{~mol} / \mathrm{L}$ for europium. No one of these isotherms $\left(q_{e}\right.$ versus $\left.C_{e}\right)$ attained a plateau. Therefore, they were surveyed by means of the adsorption isotherm model of Freundlich, using both linear and nonlinear equations, whose results were identical. The values of $1 / n$ were higher than 1 in all cases. The obtained straight lines are shown in Figure 5. When Langmuir and Langmuir-Freundlich models were applied the slopes of the lines were negative; therefore, data were not well fitted to these models. 
TABLE 1: Kinetics models applied to experimental data and parameters evaluated for $[\mathrm{La}(\mathrm{III})]=5.7 \times 10^{-5} \mathrm{M}$ and $[\mathrm{Eu}(\mathrm{III})]=6.5 \times 10^{-5} \mathrm{M}$ adsorption on hydroxyapatite at room temperature and $\mathrm{pH}_{\mathrm{eq}}=5.75 \pm 0.03$.

\begin{tabular}{|c|c|c|c|}
\hline Models, equations, and [conditions] & Parameters & $\mathrm{La}(\mathrm{III})$ & $\mathrm{Eu}(\mathrm{III})$ \\
\hline $\begin{array}{l}\text { Pseudo-second-order } \\
\qquad \frac{t}{q_{t}}=\frac{1}{K_{2}} q_{\max }^{2}+\frac{1}{q_{e}} t\end{array}$ & $\begin{array}{l}K_{2}(\mathrm{~g} / \mathrm{mg} \text { minute }) \\
q_{\max }(\mathrm{mg} / \mathrm{g})\end{array}$ & $\begin{array}{c}8.5 \\
0.25\end{array}$ & $\begin{array}{l}0.65 \\
0.98\end{array}$ \\
\hline \multicolumn{4}{|l|}{ Intraparticle mass transfert diffusion } \\
\hline $\begin{array}{l}q_{t}=K_{\mathrm{IP}} t^{1 / 2} \\
{[t=0 \text { to } 1 \text { minute }]}\end{array}$ & $K_{\mathrm{IP}}\left(\mathrm{mg} / \mathrm{g} \mathrm{minute}^{1 / 2}\right)$ & 0.04 & 0.22 \\
\hline $\begin{array}{l}q_{t}=K_{\mathrm{IP}} t^{1 / 2}+C \\
{[\mathrm{La}(\mathrm{III}): t=1 \text { to } 7 \text { minutes }]} \\
{[\mathrm{Eu}(\mathrm{III}): t=1 \text { to } 15 \text { minutes }]}\end{array}$ & $\begin{array}{c}K_{\mathrm{IP}}\left(\mathrm{mg} / \mathrm{g} \text { minute } \mathrm{t}^{1 / 2}\right) \\
C(\mathrm{mg} / \mathrm{g})\end{array}$ & $\begin{array}{c}5.5 \times 10^{-4} \\
0.17\end{array}$ & $\begin{array}{c}0.026 \\
0.32\end{array}$ \\
\hline $\begin{array}{l}q_{t}=K_{\mathrm{IP}} t^{1 / 2}+q_{\max } \\
{[\mathrm{La}(\mathrm{III}): t=1 \text { to } 7 \text { minutes] }} \\
{[\mathrm{Eu}(\mathrm{III}): t=15 \text { to } 60 \text { minutes] }}\end{array}$ & $\begin{array}{c}K_{\mathrm{IP}}(\mathrm{mg} / \mathrm{g} \text { minute } \\
q_{\max }(\mathrm{mg} / \mathrm{g})\end{array}$ & $\begin{array}{c}7.3 \times 10^{-6} \\
0.23\end{array}$ & $\begin{array}{c}1.5 \times 10^{-3} \\
0.92\end{array}$ \\
\hline
\end{tabular}

TABLE 2: Maximum lanthanum and europium adsorption capacities $\left(q_{\max }\right)$ on hydroxyapatite and other adsorbents.

\begin{tabular}{|c|c|c|c|c|}
\hline Adsorbents & REE ion & $q_{\max }(\mathrm{mg} / \mathrm{g})$ & $q_{\max }(\mathrm{mmol} / \mathrm{g})$ & References \\
\hline \multirow{2}{*}{ Hydroxyapatite } & $\mathrm{La}(\mathrm{III})$ & $0.25 \pm 0.01$ & 0.006 & Present work \\
\hline & $\mathrm{Eu}(\mathrm{III})$ & $0.94 \pm 0.01$ & 0.002 & Present work \\
\hline Sargassum biomass & $\mathrm{La}(\mathrm{III})$ & & $0.8-0.9$ & [23] \\
\hline $\mathrm{BaCO}_{3}$ & $\mathrm{Eu}(\mathrm{III})$ & 16 & 0.1 & {$[26]$} \\
\hline $\mathrm{TiO}_{2}$ & $\mathrm{La}(\mathrm{III})$ & $0.49 \pm 0.01$ & & {$[28]$} \\
\hline ZSM-5 zeolite & $\mathrm{Eu}(\mathrm{III})$ & & $2.2 \times 10^{-5}$ & {$[30]$} \\
\hline $\mathrm{TiO}_{2}$ & $\mathrm{Eu}(\mathrm{III})$ & & 0.01 & {$[33]$} \\
\hline Inmobilized pseudomonas aeruginosa & $\mathrm{La}(\mathrm{III})$ & & 0.342 & {$[32]$} \\
\hline TiAlPH & $\mathrm{Eu}(\mathrm{III})$ & $20-30$ & & {$[35]$} \\
\hline
\end{tabular}

Table 3 shows the data for the systems fitted by means of the Freundlich $1 / n>1$ model. The values of $1 / n$ were 4.7 and 2.3 for $\mathrm{La}(\mathrm{III})$ and 1.85 for $\mathrm{Eu}(\mathrm{III})$. An example of this behavior was found for the adsorption isotherm of atrazine by activated phosphoric acid-treated biomass [47].

The Freundlich model is based on an empirical equation that considers the adsorption on a heterogeneous surface supporting sites of varied affinities and implies that the energy distribution for the adsorption sites is exponential in nature [48]. The values of $K_{F}$, the binding constant, and $1 / n$, the exponent, determine the steepness and curvature of the isotherm. The rates of adsorption and desorption vary with the adsorption energy of the sites; the possibility exists for more than one monomolecular layer of adsorptive coverage as $C_{e}$ gets larger. Moreover, it has even been considered that at high concentrations, the equation would fail to fit experimental results. Data of the present research shows that for two different ranges of $\left[\mathrm{La}^{3+}\right]_{i}$ the Freundlich model with $1 / n>1$ adequately fitted and that $K_{F}$ values depend on the initial concentration of lanthanum (see Table 3). Apart from the homogeneous surface, the Freundlich equation is also suitable for a highly heterogeneous surface; an adsorption isotherm lacking a plateau is an indication of a multilayer adsorption [49].
The values of $1 / n$, if less than 1 , define a normal-type adsorption and are found in many cases. The systems with $1 / n$ values higher than 1 are less common, but they has been found for example: (a) with high concentration of solutions and high retention capacity of sorbent [50]; (b) being high both parameters [51] and (c) with low concentrations of equilibrium solutions and a high capacity sorbent [52] as the conditions in the present research. A possible explanation could be a cooperative-type adsorption $[47,53]$. The cooperative effects involve both fluid-fluid interactions and fluid-solid interactions with suitably located sites, and the adsorption is enhanced when these sites are bridged with clusters of water molecules, which fill the microporosity. The values found in the present research imply that the REE adsorption onto hydroxyapatite is a cooperative-type adsorption, which could be linked both to the nature of the solid and to the behavior of these ions.

The higher the $K_{F}$ value, the greater the adsorption intensity and the results of the present research indicate a better adsorption for europium $\left(K_{F}=1.59 \mathrm{~L} / \mathrm{mg}\right)$ than for lanthanum $\left(K_{F}=1.17 \mathrm{~L} / \mathrm{mg}\right)$ at equivalent initial concentrations, even if the chemical behaviour of both ions seems to be similar. These values of $K_{F}$ are in the same order of magnitude than the values obtained for the normaltype adsorption system hydroxyapatite-fluoride [54] and the cooperative-type system mentioned previously [47]. 
TABle 3: Parameters of the Freundlich model $\left(\log q_{e}=1 / n \log C_{e}+\log K_{F}\right)$ applied to experimental data for La(III) and Eu(III) adsorption on hydroxyapatite at room temperature and $\mathrm{pH}_{\mathrm{eq}}=5.75 \pm 0.03$.

\begin{tabular}{lccc}
\hline Parameters & {$[\mathrm{La}(\mathrm{III})]_{\mathrm{I}}=3.3 \times 10^{-5}-2.2 \times 10^{-4} \mathrm{M}$} & {$[\mathrm{La}(\mathrm{III})]_{\mathrm{I}}=1.7-3.6 \times 10^{-4} \mathrm{M}$} & {$[\mathrm{Eu}(\mathrm{III})]_{\mathrm{I}}=1.9-4 \times 10^{-4} \mathrm{M}$} \\
\hline $1 / n$ & 4.7 & 2.30 & 1.85 \\
$K_{F}(\mathrm{~L} / \mathrm{mg})$ & 0.12 & 1.17 & 1.59 \\
$R^{2}$ & 0.96 & 0.99 & 0.99 \\
\hline
\end{tabular}

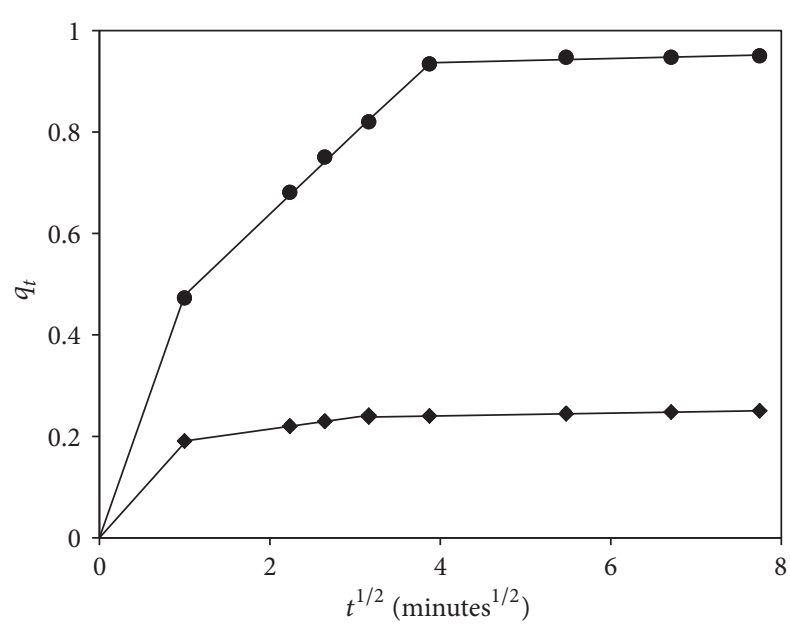

FIGURE 4: Amount of REEs adsorbed on synthetic hydroxyapatite $\left(q_{t}\right)$ and fitting of data to the intraparticle mass transfer diffusion model. Rhombus: La(III) and circles: Eu(III). The equations of the lines are the following: $q_{t}=0.19 t^{1 / 2}\left(R^{2}=1\right) ; q_{t}=0.024 t^{1 / 2}+0.17$ $\left(R^{2}=0.94\right)$ and $q_{t}=0.003 t^{1 / 2}+0.22\left(R^{2}=0.7\right)$ for La(III) and $q_{t}=0.47 t^{1 / 2}\left(R^{2}=1\right) ; q_{t}=0.16 t^{1 / 2}+0.31\left(R^{2}=0.999\right)$ and $q_{t}=$ $0.004 t^{1 / 2}+0.92\left(R^{2}=0.82\right)$ for $\mathrm{Eu}(\mathrm{III})$.

The adsorption percentages were dependent on the initial concentrations as shown in Figure 6. When $[\mathrm{REE}]_{\mathrm{i}}>1.5 \times$ $10^{-4} \mathrm{M}$, these values are $95.9 \pm 0.9 \%$ for $\mathrm{La}(\mathrm{III})$ and $96.3 \pm 0.5 \%$ for $\mathrm{Eu}(\mathrm{III})$.

The formation of hydrolyzed REE species depends on metal concentration and $\mathrm{pH}$ of solution $[36,55]$. The species distribution diagrams [56] for $\mathrm{La}$ (III) and $\mathrm{Eu}$ (III) as a function of $\mathrm{pH}$ (at their minimal initial concentrations of the present work) show that at equilibrium $\mathrm{pH}(5.7 \pm 0.03)$, trivalent lanthanum and europium are the only ionic species present in the solutions, $\left(\mathrm{La}(\mathrm{OH})^{2+}\right.$ is formed at $\mathrm{pH}$ between 6.8 and $9.5, \mathrm{La}(\mathrm{OH})_{3}$ at $\mathrm{pH}>8.5$, and $\mathrm{Eu}(\mathrm{OH})_{3}$ at $\left.\mathrm{pH}>6.6\right)$. Therefore, it can be inferred that adsorption of these ions on hydroxyapatite is not due to the precipitation of hydroxides.

Cation removal from aqueous solutions by hydroxyapatite may occur through different adsorption processes (i.e., adsorption, ion-exchange, surface complexation, and coprecipitation) depending on the experimental conditions and nature of both adsorbing cations and hydroxyapatite itself. At $\mathrm{pH}$ values higher than zpc, the adsorbent surface becomes negative due to adsorption of $\mathrm{OH}^{-}$from the solution. Increase in electrostatic attraction forces, acting between the surface and the cations from the solution, contributes to a greater action adsorption at higher $\mathrm{pHs}$. The equilibrium

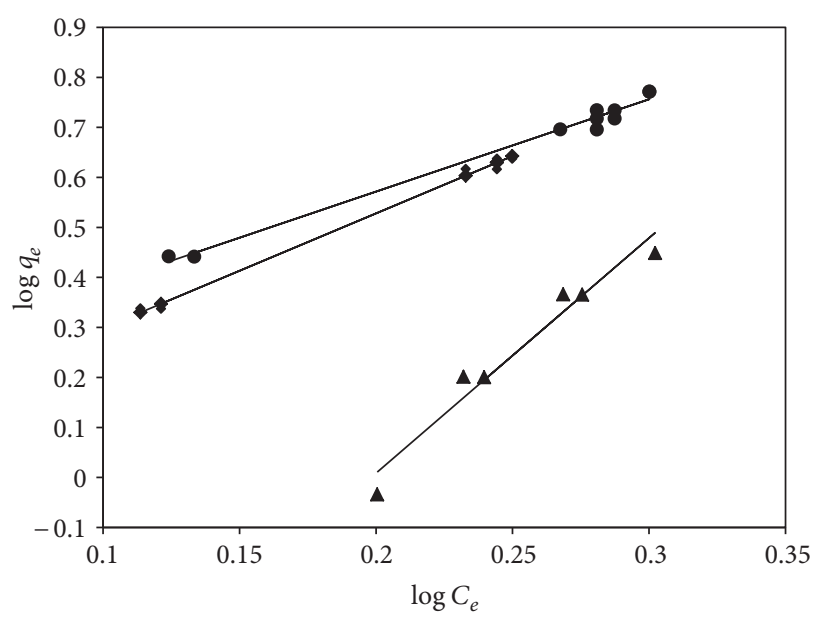

FIGURE 5: Isotherms of Freundlich model with $1 / n>1$ for REEs on synthetic hydroxyapatite. The equations of the lines are: $\log q_{e}=$ $2.3 \log C_{e}+0.07\left(R^{2}=0.995\right)$ for [La(III)]: $1.7 \times 10^{-4}-3.6 \times 10^{-4} \mathrm{~mol} / \mathrm{L}$ (rhombus); $\log q_{e}=4.7 \log C_{e}-0.9\left(R^{2}=0.96\right)$ for $[\mathrm{La}(\mathrm{III})]: 3.3 \times$ $10^{-5}-2.2 \times 10^{-4} \mathrm{~mol} / \mathrm{L}$ (triangles); $\log q_{e}=1.8 \log C_{e}+0.2\left(R^{2}=\right.$ 0.99 ) for [Eu(III)]: $1.9 \times 10^{-4}-4 \times 10^{-4} \mathrm{~mol} / \mathrm{L}$ (circles).

$\mathrm{pH}$ values $(5.7 \pm 0.03)$ are acid regarding the $\mathrm{zpc}$ value of hydroxyapatite (7.68); moreover, it is interesting to note the value of acidic surface sites $(3.70 \mathrm{meq} / \mathrm{g})$ and the basic surface sites $(0.37 \mathrm{meq} / \mathrm{g})$ for the behavior of the system. The results of the present investigation could not be explained considering adsorption of $\mathrm{OH}^{-}$from the solution because the equilibrium $\mathrm{pH}$ is less than the zpc of the hydroxyapatite; in this case, its surface becomes positive like trivalent REEs. Then, only a surface complexation or an ion exchange with calcium could be suggested.

3.4. Thermodynamic Parameters. Batch adsorption experiments as described previously were performed in duplicate at temperatures of $293,303,313$, and $323 \mathrm{~K}$ by using the following initial concentrations: $3.6 \times 10^{-4} \mathrm{~mol} / \mathrm{L}$ for $\mathrm{La}(\mathrm{III})$ and $4.6 \times$ $10^{-4} \mathrm{~mol} / \mathrm{L}$ for $\mathrm{Eu}(\mathrm{III})$ ions. Equilibrium $\mathrm{pH}$ was 5.7. Thermodynamic parameters were deduced by means of the dependence of the distribution coefficient $K_{d}$ on temperature. The results show that the $\mathrm{La}(\mathrm{III})$ and $\mathrm{Eu}$ (III) adsorptions proportionally increase with temperature. This result is expected; at higher temperature cations are moving faster, which retards specific or electrostatic interactions that become weaker. The ions become smaller because solvation is reduced. The standard enthalpy changes for adsorption $\left(\Delta H^{\circ}\right)$ were estimated 
TABLE 4: Changes of enthalpy, entropy, and Gibbs-free energy for the adsorption of lanthanum and europium on hydroxyapatite.

\begin{tabular}{lcccc}
\hline REE & $\Delta H^{\circ}(\mathrm{kJ} / \mathrm{mol})$ & $\Delta S^{\circ}(\mathrm{kJ} / \mathrm{mol} \mathrm{K})$ & $T,(\mathrm{~K})$ & $\Delta G^{\circ}\left(\mathrm{kJ} / \mathrm{mol}^{2}\right.$ \\
\hline & 5.9 & 0.08 & 293 & -16.2 \\
$\mathrm{La}(\mathrm{III})$ & & & 303 & -17.0 \\
& & & 313 & -17.8 \\
\hline & & & 323 & -18.5 \\
$\mathrm{Eu}(\mathrm{III})$ & 34.1 & 0.17 & 293 & -15.2 \\
& & & 303 & -18.9 \\
& & & 313 & -20.2 \\
\hline
\end{tabular}

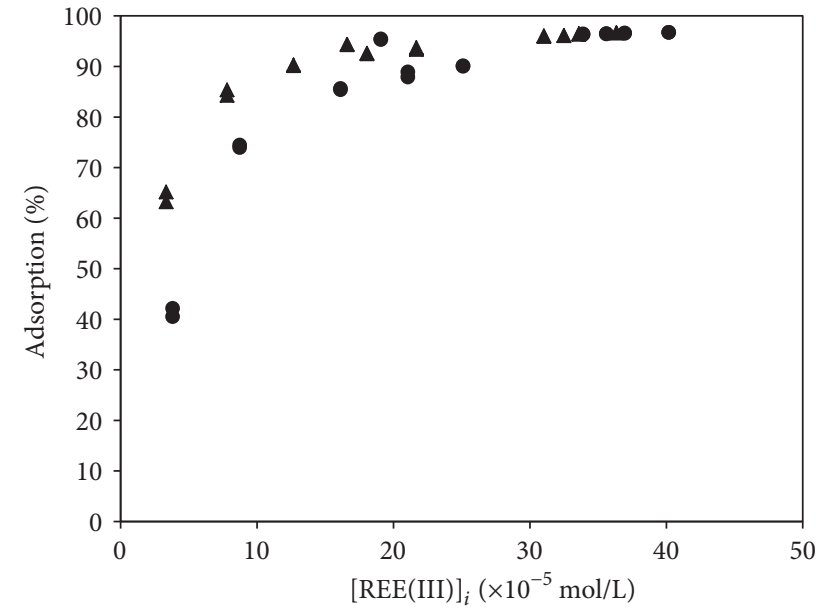

$\Delta \mathrm{La}(\mathrm{III})$

- $\mathrm{Eu}(\mathrm{III})$

FIGURE 6: Adsorption percentages on hydroxyapatite of La(III) and $\mathrm{Eu}(\mathrm{III})$ versus initial concentrations.

from the slope of straight line plot log $K_{d}$ versus1/T (Figure 7), according to the Van't Hoff equation [57] in lineal form:

$$
\log K_{d}=\frac{\Delta H^{\circ}}{2.303 R}\left(\frac{1}{T}\right)+\frac{\Delta S^{\circ}}{2.303 R},
$$

where $K_{d}$ is the distribution coefficient value $\left(\mathrm{cm}^{3} / \mathrm{g}\right)$ at temperature $T$ in Kelvin, $R$ is the ideal gas constant $\left(R=8.31 \times 10^{-3} \mathrm{~kJ} / \mathrm{mol}\right)$, and $\Delta S^{\circ}$ is the entropy change. The values of $\Delta H^{\circ}$ and $\Delta S^{\circ}$ for $\mathrm{La}(\mathrm{III})$ and $\mathrm{Eu}(\mathrm{III})$ adsorption processes on hydroxyapatite are given in Table 4 . The positive values of $\Delta H^{\circ}$ indicate that these processes are of endothermic nature; because they are lesser than $40 \mathrm{~kJ} / \mathrm{mol}$, they are probably due to physical adsorption [58]. The values of $\Delta S^{\circ}$ (see Table 4) are positive and reveal some structural changes in adsorbate and adsorbent during the process; these changes cause an increase of disorder in the solid-solution system. This disorder could be the result of extratranslational entropy gained by the water molecules previously adsorbed onto adsorbent but displaced by metal ions.

Changes in standard Gibbs-free energy $\left(\Delta H^{\circ}\right)$ were also evaluated by using the following thermodynamic equation:

$$
\Delta G^{\circ}=\Delta H^{\circ}-T \Delta S^{\circ}
$$

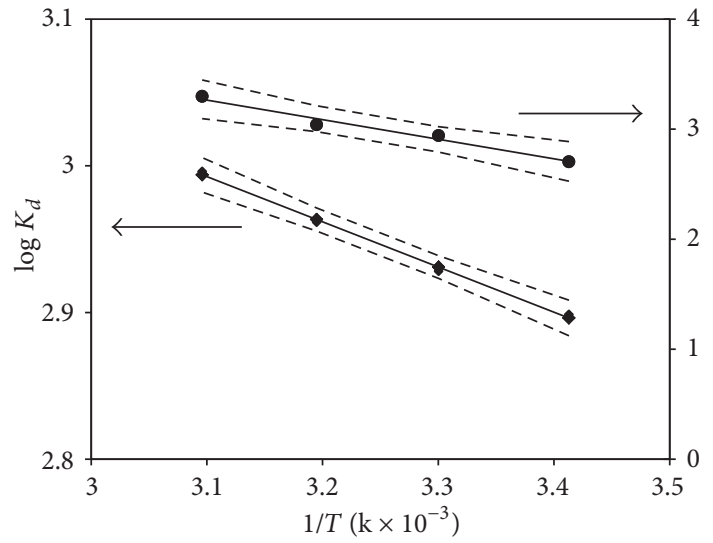

Figure 7: Diagram of $\log K_{d}$ versus $1 / T$. The equations of the lines are: $\log K_{d}=-308(1 / T)+4\left(R^{2}=0.996\right)$ for La(III), rhombus and $\log K_{d}=-1780(1 / T)+8.8\left(R^{2}=0.97\right)$ for $\mathrm{Eu}(\mathrm{III})$, circles. $95 \%$ confidence intervals of the regression lines are included.

The values of $\Delta G^{\circ}$ are the fundamental criterion of spontaneity (see Table 4); their negative values reveal that the adsorptions occur spontaneously at each temperature and confirm the thermodynamically feasibility of the adsorption processes. The obtained thermodynamic data provide valuable information for the design of improved adsorption schemes for treating lanthanide ions from waste solutions using synthetic hydroxyapatite.

\section{Conclusions}

In this study, the hydroxyapatite was successfully synthesized by the precipitation method; a porous and pure material was obtained with structural, chemical, and superficial characteristics adequate to be used as adsorbent material for removing $\mathrm{La}(\mathrm{III})$ and $\mathrm{Eu}(\mathrm{III})$ ions present in aqueous solutions. The equilibrium of adsorption for these lanthanide ions was quickly achieved. The synthesized hydroxyapatite showed an adsorption efficiency of $0.25 \mathrm{mg} / \mathrm{g}$ and $0.94 \mathrm{mg} / \mathrm{g}$ for La(III) and $\mathrm{Eu}(\mathrm{III})$, respectively. The kinetic data corresponded very well to the pseudo-second-order equation, and the Freundlich adsorption isotherm with $1 / n>1$ adequately fitted the experimental values for both ions indicating a multilayer and cooperative-type process. Adsorpted amounts for La(III) and $\mathrm{Eu}(\mathrm{III})$ were positively dependent on temperature. 
The thermodynamic values showed that the absorption processes for La(III) and Eu(III) on hydroxyapatite are endothermic and spontaneous. These data present to hydroxyapatite as a viable and economic alternative for the removal of $\mathrm{La}$ (III) and $\mathrm{Eu}(\mathrm{III})$ present in aqueous solutions because good results were obtained in batch mode.

\section{Acknowledgments}

Financial support from the ININ Project no. CB-904 and assistance with obtaining the SEM/EDS measurements of Mr. J. Pérez-Del Prado are gratefully appreciated.

\section{References}

[1] I. Olmez, E. R. Sholkovitz, D. Hermann, and R. P. Eganhouse, "Rare earth elements in sediments off southern California: a new anthropogenic indicator," Environmental Science and Technology, vol. 25, no. 2, pp. 310-316, 1991.

[2] I. N. Sax, Dangerous Properties of Industrial Materials, Wiley and Sons, New York, NY, USA, 1984.

[3] F. D. Tillman, S. L. Bartelt-Hunt, V. A. Craver, J. A. Smith, and G. R. Alther, "Relative metal ion sorption on natural and engineered sorbents: batch and column studies," Environmental Engineering Science, vol. 22, no. 3, pp. 400-410, 2005.

[4] T. D. Reynolds, Unit Operations and Processes in Environmental Engineering, PWS Publishing, New York, NY, USA, 1992.

[5] V. E. Badillo-Almaraz and J. Ly, "Calcium sorption on hydroxyapatite in aqueous solutions: reversible and nonreversible components," Journal of Colloid and Interface Science, vol. 258, no. 1, pp. 27-32, 2003.

[6] N. C. C. Da Rocha, R. C. De Campos, A. M. Rossi, E. L. Moreira, A. D. F. Barbosa, and G. T. Moure, "Cadmium uptake by hydroxyapatite synthesized in different conditions and submitted to thermal treatment," Environmental Science and Technology, vol. 36, no. 7, pp. 1630-1635, 2002.

[7] F. Granados-Correa, J. Bonifacio-Martínez, and J. SerranoGómez, "Synthesis and characterization of calcium phosphate and its relation to $\mathrm{Cr}(\mathrm{VI})$ adsorption properties," Revista Internacional de Contaminacion Ambiental, vol. 26, no. 2, pp. 129-134, 2010.

[8] R. C. Moore, K. Holt, H. Zhao et al., "Sorption of $\mathrm{Np}(\mathrm{V})$ by synthetic hydroxyapatite," Radiochimica Acta, vol. 91, no. 12, pp. 721-727, 2003.

[9] T. Matsuda, C. Yamanaka, and M. Ikeya, "ESR study of $\mathrm{Gd}^{3+}$ and $\mathrm{Mn}^{2+}$ ions sorbed on hydroxyapatite," Applied Radiation and Isotopes, vol. 62, no. 2, pp. 353-357, 2005.

[10] M. I. Kay, R. A. Young, and A. S. Posner, "Crystal structure of hydroxyapatite," Nature, vol. 204, no. 4963, pp. 1050-1052, 1964.

[11] D. E. C. Corbridge, Phosphoruos, An Outline of is Chemistry, Biochemistry and Technology, Elsevier, Amsterdam, The Netherlands, 1985.

[12] A. J. Tofe, "Chemical decontaminations using natural or artificial bone," U.S. Patent 5711015, 1998.

[13] E. Andronescu, E. Stefan, E. Dinu et al., "Hydroxyapatite synthesis," European Ceramic, vol. 206, pp. 1595-1598, 2002.

[14] A. D. Papargyris, A. I. Botis, and S. A. Papargyri, "Synthetic routes for hydroxyapatite powder production," Key Engineering Materials, vol. 206-213, pp. 83-86, 2002.
[15] S. K. Ghosh, S. Datta, and S. K. Roy, "Solution combustion synthesis of calcium hydroxyapatite nanoparticles," Transactions of the Indian Ceramic Society, vol. 63, pp. 27-32, 2004.

[16] S. K. Nandi, B. Kundu, S. K. Ghosh, D. K. De, and D. Basu, "Efficacy of nano-hydroxyapatite prepared by an aqueous solution combustion technique in healing bone defects of goat," Journal of Veterinary Science, vol. 9, no. 2, pp. 183-191, 2008.

[17] T. Hattori, Y. M. Iwadate, and T. Kato, "Hydrothermal synthesis of hydroxyapatite from calcium acetate and trietyl phosphate," Advanced Ceramic Materials, vol. 3, pp. 426-428, 1988.

[18] K. Dahanayake and S. M. N. D. Subasinghe, "Mineralogical, chemical and solubility variations in the Eppawala phosphate deposit of Sri Lanka-a case for selective mining for fertilizers," Fertilizer Research, vol. 28, no. 2, pp. 233-238, 1991.

[19] J. C. Bünzli and G. Choppin, Lanthanide Probes in Life, Chemical and Earth Sciences, Elsevier, Amsterdam, The Netherlands, 1989.

[20] M. D. Alba, R. Alvero, A. I. Becerro, M. A. Castro, A. MuñozPaez, and J. M. Trillo, "Study of the reversibility on the local $\mathrm{La}^{3+}$ environment after thermal and drying treatments in lanthanum-exchanged smectites," Nuclear Instruments and Methods in Physics Research B, vol. 133, no. 1-4, pp. 34-38, 1997.

[21] P. Beneš, K. Štamberg, L. Široký, and J. Mizera, "Radiotracer study of sorption of europium on Gorleben sand from aqueous solutions containing humic substances," Journal of Radioanalytical and Nuclear Chemistry, vol. 254, no. 2, pp. 231-239, 2002.

[22] C. L. Chen, X. K. Wang, and M. Nagatsu, "Europium adsorption on multiwall carbon nanotube/iron oxide magnetic composite in the presence of polyacrylic acid," Environmental Science and Technology, vol. 43, no. 7, pp. 2362-2367, 2009.

[23] V. Diniz and B. Volesky, "Biosorption of La, Eu and Yb using Sargassum biomass," Water Research, vol. 39, no. 1, pp. 239-247, 2005.

[24] A. M. El-Kamash, B. El-Gammal, and A. A. El-Sayed, "Preparation and evaluation of cerium(IV) tungstate powder as inorganic exchanger in sorption of cobalt and europium ions from aqueous solutions," Journal of Hazardous Materials, vol. 141, no. 3, pp. 719-728, 2007.

[25] Q. H. Fan, X. L. Tan, J. X. Li, X. K. Wang, W. S. Wu, and G. Montavon, "Sorption of $\mathrm{Eu}(\mathrm{III})$ on attapulgite studied by batch, XPS, and EXAFS techniques," Environmental Science and Technology, vol. 43, no. 15, pp. 5776-5782, 2009.

[26] F. Granados-Correa and M. Jiménez-Reyes, "Combustion synthesis of $\mathrm{BaCO}_{3}$ and its application for $\mathrm{Eu}(\mathrm{III})$ adsorption from aqueous solution," Separation Science and Technology, vol. 46, pp. 2360-2366, 2011.

[27] S. M. Kraemer, J. Xu, K. N. Raymond, and G. Sposito, "Adsorption of $\mathrm{Pb}(\mathrm{II})$ and $\mathrm{Eu}(\mathrm{III})$ by oxide minerals in the presence of natural and synthetic hydroxamate siderophores," Environmental Science and Technology, vol. 36, no. 6, pp. 1287-1291, 2002.

[28] S. Li, B. Hu, Z. Jiang, P. Liang, X. Li, and L. Xia, "Selective separation of $\mathrm{La}^{3+}$ and lanthanum organic complexes with nanometer-sized titanium dioxide and their detection by using fluorination-assisted electrothermal vaporization ICPAES with in-situ matrix removal," Environmental Science and Technology, vol. 38, no. 7, pp. 2248-2251, 2004.

[29] S. E. Pepper, L. C. Hull, B. N. Bottenus, and S. B. Clark, "Adsorption of lanthanum to goethite in the presence of gluconate," Radiochimica Acta, vol. 94, no. 4, pp. 229-237, 2006. 
[30] D. D. Shao, Q. H. Fan, J. X. Li et al., "Removal of Eu(III) from aqueous solution using ZSM-5 zeolite," Microporous and Mesoporous Materials, vol. 123, no. 1-3, pp. 1-9, 2009.

[31] Y. Takahashi, T. Kimura, Y. Kato, and Y. Minai, "Speciation of europium(III) sorbed on a montmorillonite surface in the presence of polycarboxylic acid by laser-induced fluorescence spectroscopy," Environmental Science and Technology, vol. 33, no. 22, pp. 4016-4021, 1999.

[32] X. Tan, Q. Fan, X. Wang, and B. Grambow, "Eu(III) sorption to $\mathrm{TiO}_{2}$ (anatase and rutile): batch, XPS, and EXAFS studies," Environmental Science and Technology, vol. 43, no. 9, pp. 3115-3121, 2009.

[33] A. C. Texier, Y. Andrès, C. Faur-Brasquet, and P. Le Cloirec, "Fixed-bed study for lanthanide ( $\mathrm{La}, \mathrm{Eu}, \mathrm{Yb})$ ions removal from aqueous solutions by immobilized Pseudomonas aeruginosa: experimental data and modelization," Chemosphere, vol. 47, no. 3, pp. 333-342, 2002.

[34] M. Zavarin, S. K. Roberts, N. Hakem, A. M. Sawvel, and A. B. Kersting, " $\mathrm{Eu}(\mathrm{III}), \mathrm{Sm}(\mathrm{III}), \mathrm{Np}(\mathrm{V}), \mathrm{Pu}(\mathrm{V})$, and $\mathrm{Pu}(\mathrm{IV})$ sorption to calcite," Radiochimica Acta, vol. 93, no. 2, pp. 93-102, 2005.

[35] P. Misaelides, S. Sarri, D. Zamboulis, G. Gallios, I. Zhuravlev, and V. V. Strelko, "Separation of europium from aqueous solutions using $\mathrm{Al}^{3+}$ - and $\mathrm{Fe}^{3+}$-doped zirconium and titanium phosphates," Journal of Radioanalytical and Nuclear Chemistry, vol. 268, no. 1, pp. 53-58, 2006.

[36] X. L. Tan, X. K. Wang, H. Geckeis, and T. H. Rabung, "Sorption of $\mathrm{Eu}(\mathrm{III})$ on humic acid or fulvic acid bound to hydrous alumina studied by SEM-EDS, XPS, TRLFS, and batch techniques," Environmental Science and Technology, vol. 42, no. 17, pp. 6532-6537, 2008.

[37] S. Kannan, F. Goetz-Neunhoeffer, J. Neubauer, and J. M. F. Ferreira, "Ionic substitutions in biphasic hydroxyapatite and $\beta$ tricalcium phosphate mixtures: structural analysis by rietveld refinement," Journal of the American Ceramic Society, vol. 91, no. 1, pp. 1-12, 2008.

[38] H. P. Boehm and M. Voll, "Basic surface oxides on carbonadsorption of acids," Carbon, vol. 8, no. 2, pp. 227-240, 1970.

[39] J. S. Noh and J. A. Schwarz, "Estimation of the point of zero charge of simple oxides by mass titration," Journal of Colloid and Interface Science, vol. 130, no. 1, pp. 157-164, 1989.

[40] A. K. Mukherji, "Simultaneous spectrophotometric determination of thorium and the rare earths with Xylenol Orange," Microchemical Journal, vol. 11, no. 2, pp. 243-254, 1966.

[41] S. K. Milonjić, A. L. Ruvarac, and M. V. Šušić, "The heat of immersion of natural magnetite in aqueous solutions," Thermochimica Acta, vol. 11, no. 3, pp. 261-266, 1975.

[42] P. Thakur, R. C. Moore, and G. R. Choppin, "Sorption of U(VI) species on hydroxyapatite," Radiochimica Acta, vol. 93, no. 7, pp. 385-391, 2005.

[43] S. Lagergren, "About the theory of so-called adsorption of soluble substances. Kunglica Svenska Vetenskapsakademiens," Habdllingar, vol. 24, pp. 1-39, 1898.

[44] C. W. Cheung, J. F. Porter, and G. Mckay, "Sorption kinetic analysis for the removal of cadmium ions from effluents using bone char," Water Research, vol. 35, no. 3, pp. 605-612, 2001.

[45] Y. S. Ho and G. McKay, "Pseudo-second order model for sorption processes," Process Biochemistry, vol. 34, no. 5, pp. 451-465, 1999.

[46] W. J. Weber and J. C. Morris, "Kinetics of adsorption on carbon from solution," Journal of the Sanitary Engineering Division, vol. 89, pp. 31-60, 1963.
[47] I. A. Udoji, W. Abdulrahman, L. G. Hassan et al., "GC/MS batch equilibrium study and adsorption isotherms of atrazine sorption by activated $\mathrm{H}_{3} \mathrm{PO}_{4}{ }^{-}$treated biomass," Journal of American Science, vol. 6, pp. 19-29, 2010.

[48] H. M. F. Freundlich, "Over the adsorption in solution," Journal of Physical Chemistry, vol. 57, pp. 385-470, 1906.

[49] J. C. Igwe and A. A. Abia, "Maize cob and husk as adsorbent for removal $\mathrm{Cd}, \mathrm{Pb}$ and $\mathrm{Zn}$ ions from waste water," The Physical Sciences, vol. 2, pp. 83-94, 2003.

[50] Y. Ran, J. Fu, A. W. Rate, and R. J. Gilkes, "Adsorption of Au(I, III) complexes on $\mathrm{Fe}, \mathrm{Mn}$ oxides and humic acid," Chemical Geology, vol. 185, no. 1-2, pp. 33-49, 2002.

[51] M. Mazari-Hiriart, C. Hernández-Eugenio, F. Rojo-Callejas, and R. Lozano-Santacruz, "Vertical variability of PCE sorption in the lacustrine clays of Mexico City," Environmental Geology, vol. 39, no. 6, pp. 595-602, 2000.

[52] S. Kleineidam, C. Schüth, and P. Grathwohl, "Solubilitynormalized combined adsorption-partitioning sorption isotherms for organic pollutants," Environmental Science and Technology, vol. 36, no. 21, pp. 4689-4697, 2002.

[53] N. J. Foley, K. M. Thomas, P. L. Forshaw, D. Stanton, and P. R. Norman, "Kinetics of water vapor adsorption on activated carbon," Langmuir, vol. 13, no. 7, pp. 2083-2089, 1997.

[54] M. Jiménez-Reyes and M. Solache-Ríos, "Sorption behavior of fluoride ions from aqueous solutions by hydroxyapatite," Journal of Hazardous Materials, vol. 180, no. 1-3, pp. 297-302, 2010.

[55] H. López-González, M. Jiménez-Reyes, M. Solache-Ríos, and A. Rojas-Hernández, "Solubility and hydrolysis of lutetium at different $\left[\mathrm{Lu}^{3+}\right]_{\text {initial }}$, Journal of Radioanalytical and Nuclear Chemistry, vol. 274, no. 1, pp. 103-108, 2007.

[56] I. Puigdomenech, "Program MEDUSA: make equilibrium diagrams using sophisticated algorithms," 2008, http://www.kemi kth.se/medusa/.

[57] J. M. Smith, H. C. VanNess, and M. M. Abbott, Introduction to Chemical Engineering Thermodynamics, McGraw Hill, New York, NY, USA, 2005.

[58] F. Helfferich, Ion Exchange, McGraw Hill, New York, NY, USA, 1962. 

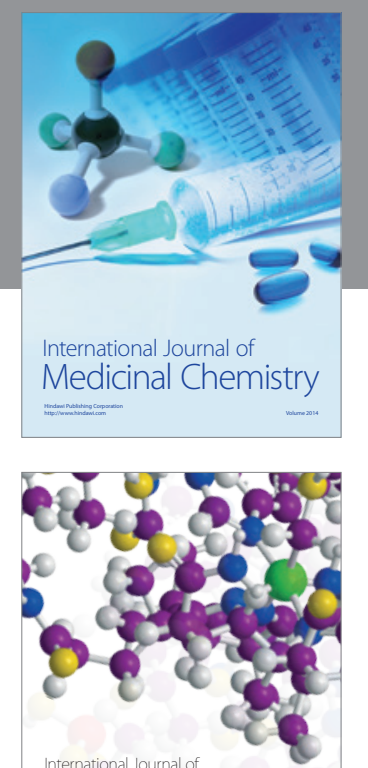

\section{Carbohydrate} Chemistry

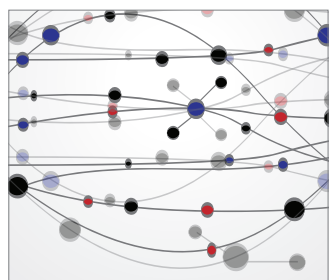

The Scientific World Journal
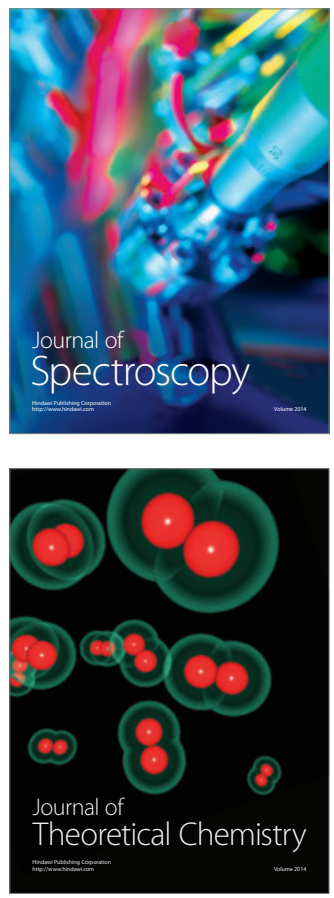
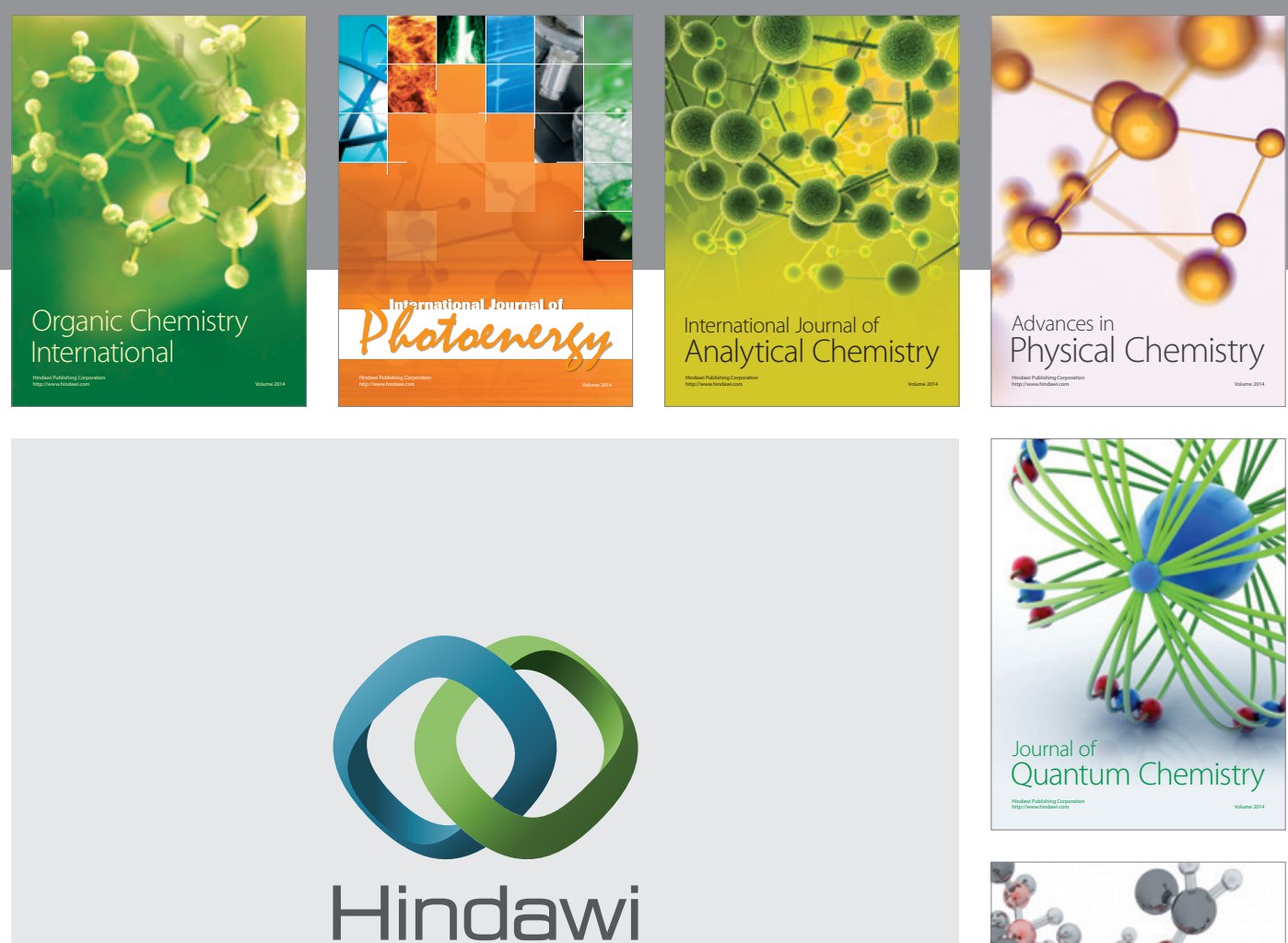

Submit your manuscripts at

http://www.hindawi.com

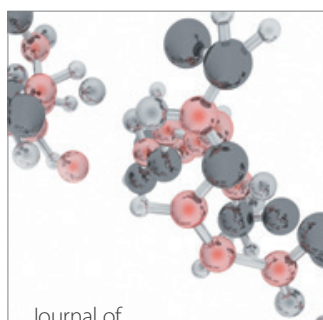

Analytical Methods

in Chemistry

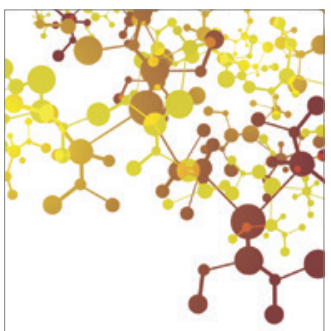

Journal of

Applied Chemistry

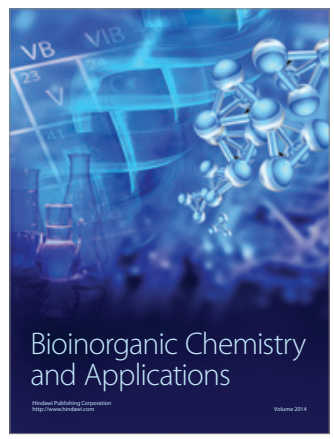

Inorganic Chemistry
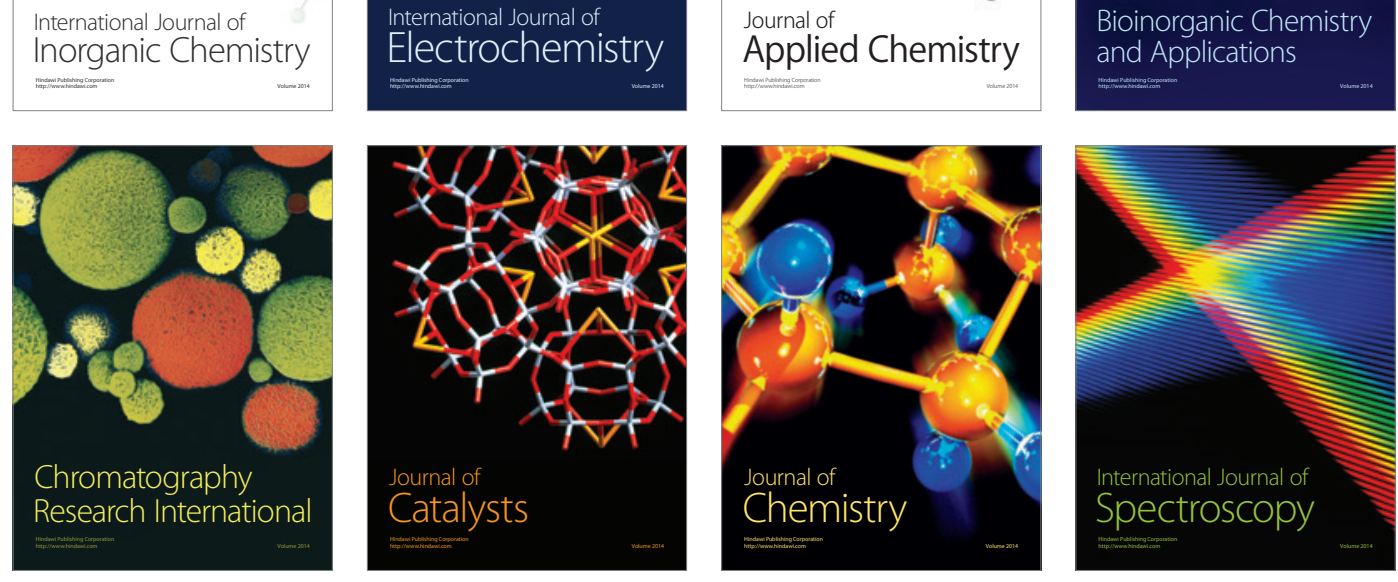